\title{
Evaluation of Biliary Secretory Immunoglobulin-A in Recipients of Living- Donor Liver Transplantation
}

Kentaro Yamagiwa ${ }^{1, *}$, Yusuke lizawa ${ }^{1}$, Motoyuki Kobayashi ${ }^{1}$, Toru Shinkai ${ }^{1}$, Takashi Hamada ${ }^{2}$, Shugo Mizuno ${ }^{2}$, Masanobu Usui ${ }^{2}$, Hiroyuki Sakurai ${ }^{2}$, Masami Tabata², Shuji Isaji ${ }^{2}$, Shintaro Yagi ${ }^{3}$, Taku lida ${ }^{3}$, Tomohide Hori ${ }^{3}$, Koji Fujii ${ }^{4}$ and Hajime Yokoi ${ }^{5}$

${ }^{1}$ Department of Surgery, Mie Prefectural Shima Hospital, Japan

${ }^{2}$ Department of Hepatobiliary-Pancreatic Transplant Surgery, Mie University Graduate School of Medicine, Japan

${ }^{3}$ Department of Hepatobiliary-Pancreatic Surgery and Transplantation, Graduate School of Medicine, Kyoto University, Japan

${ }^{4}$ Department of Surgery, Yamada Red Cross Hospital, Japan

${ }^{5}$ Department of Surgery, Mie Chuo Medical Center, Japan

\section{Abstract}

Introduction: The importance of measuring Secretory Immunoglobulin A (slg-A) levels in clinical samples from the recipients of liver transplantation is still unclear. An observational study was conducted to investigate the importance of biliary slg-A in the early period after Living-Donor Liver Transplantation (LDLT).

Methods: The biliary slg-A level $(\mu \mathrm{g} / \mathrm{ml})$ of 18 patients who underwent LDLT, and a control group of 5 patients who underwent Choledochotomy (CDT) in the Department of Hepatobiliary-Pancreatic Transplant Surgery of Mie University Hospital between 2003 and 2005 was measured on Postoperative Day 7 (POD 7). The biliary slg-A levels were compared with 11 clinical variables including portal venous Interleukin (IL)-6 levels and Portal Venous Pressure (PVP), on POD 7 in the LDLT group.

Results: The biliary slg-A levels in the LDLT group (102.8 \pm 74.8$)$ were significantly higher $(p=0.014)$ than in the CDT group $(11.7 \pm 5.6)$. Postoperative complications developed in 6 patients $(33 \%)$ in the LDLT group, but there were no significant differences between the biliary slg-A levels according to whether the patients had developed postoperative complications. There were significant positive correlations between the biliary slg-A levels and portal venous IL-6 ( $p<0.006)$ levels, PVP values $(p<0.015)$, and serum T-Bil $(p<0.023)$ values in the LDLT group.

Conclusions: The measurement of biliary sig-A in the early period after LDLT is thought to be useful for analyzing postoperative complications with high PVP and hyperbilirubinemia.

Keywords: sIg-A; Bile; LDLT

Abbreviations: sIg-A: Secretory Immunoglobulin A; LDLT: Living-Donor Liver Transplantation; CDT: Choledochotomy; POD: Postoperative Day; IL: Interleukin; PVP: Portal Venous Pressure; BECs: Biliary Epithelial Cells; pIgR: Polymerized Immunoglobulin Receptor; OLT: Orthotopic Liver Transplantation; TNF: Tumor Necrosis Factor; HCV: Hepatitis C Virus; HBV: Hepatitis B Virus; 3D-CT: Computed Tomography; Graft-To-Recipient Body Weight Ratio GRWR: Graft-To-Recipient Body Weight Ratio; GV: Graft Volume; MELD: Model for End-stage Liver Disease; CP: ChildPugh; UW: University of Wisconsin; HV: Hepatic Vein; IVC: Inferior Vena Cava; ELISA: Enzyme-Linked Immunosorbent Assay; CLEIA: Chemiluminescent Enzyme Immunoassay; T-Bil: Total Bilirubin; ALT: Alanine Aminotransferase; SECs: Sinusoidal Endothelial Cells; PVE: Portal Vein Embolization;

\section{Introduction}

Secretory immunoglobulin-A (sIg-A) is the major protein in bile, and it is the major and characteristic immunoglobulin of the mucosal immune system [1]. The important function of sIg-A in the intestine is to prevent bacteria and enteric viruses from attaching to and penetrating intestinal epithelial cells, by binding to antigens [2]. Part of the biological function of biliary sIg-A is thought to be to protect the biliary tract and upper intestinal tract after bile flows into the duodenum, but its function remains largely unknown [3]. Most of the sIg-A in human bile is synthesized by plasma cells located adjacent to the bile duct wall, and almost all of the remainder is thought to be transported from plasma into human bile across Biliary Epithelial Cells (BECs) by the Polymerized Immunoglobulin Receptor (pIgR) [1,4]. There were two studies in which biliary sIg-A were measured after Orthotopic Liver Transplantation (OLT), and one showed that biliary sIg-A levels of OLT patients at Post Operative Day (POD) 7 were significantly higher than in patients who underwent endoscopic bile drainage with gallstones [5], and the other suggested serum sIg-A played an important role in rejection after OLT better than biliary sIg-A [6]. In the recent study, the concentration of fecal sIg-A was shown to be significantly lower in the patients during 2 years after liver transplantation than in the healthy volunteers, and the finding was thought to be due to the effects of immunosuppressive agents, and no significant correlations between fecal sIg-A levels and gut bacteria, serum interleukin (IL)-6 levels, and serum Tumor Necrosis Factor (TNF)-a levels were found after the liver transplantation [7]. There was another study of serum sIg-A during major abdominal surgery besides liver transplantation [8]. Fujita et al. showed a positive correlation between portal venous interleukin (IL)-6 levels and peripheral venous sIg-A levels during major abdominal surgery, but not IL-1 $\beta$, and suggested that portal

*Corresponding author: Kentaro Yamagiwa, MD, Director, Department of Surgery, Mie Prefectural Shima Hospital Ugata 1257, Agocho, Shima City, Mie, Japan 517-0595, Tel: +81-599-43-0501; Fax: +81-599-43-6109; E-mail: yamagiwa@shimahp.pref.mie.jp

Received March 14, 2012; Accepted May 17, 2012; Published May 22, 2012

Citation: Yamagiwa K, lizawa Y, Kobayashi M, Shinkai T, Hamada T, et al. (2012) Evaluation of Biliary Secretory Immunoglobulin-A in Recipients of Living-Donor Liver Transplantation. J Liver 1:106. doi:10.4172/2167-0889.1000106

Copyright: (c) 2012 Yamagiwa K, et al. This is an open-access article distributed under the terms of the Creative Commons Attribution License, which permits unrestricted use, distribution, and reproduction in any medium, provided the original author and source are credited. 
venous IL-6 stimulates sIg-A synthesis and/or return of sIg-A from the bile into the blood in association with postoperative cholestatic liver damage [8]. The importance of measuring sIg-A levels in clinical samples from the recipients of liver transplantation is still unclear. To our knowledge no studies that analyzed the importance of biliary sIg-A levels after Living-Donor Liver Transplantation (LDLT) have ever been conducted.

The purpose of the present study was to investigate the importance of biliary sIg-A after LDLT by defining the relationships between the biliary sIg-A and their various data, clinical characteristics and outcomes in the LDLT patients on POD 7.

\section{Patients and Methods}

Eighteen adult patients (8 men and 10 women, aged 34-65 years) who underwent LDLT (LDLT group), 5 patients (4men and 1 woman, aged 52-81 years) who underwent open Choledochotomy and Cholecystectomy (CDT group) for common bile duct stones as a control group, between October 2003 and September 2005 in the Department of Hepatobiliary-Pancreatic Transplant Surgery, Mie University Hospital were enrolled in the study. The study protocol was approved by the Medical Ethics Committee of Mie University, and the study was performed in accordance with the ethical standards established in the 1975 Declaration of Helsinki. Written informed consent was obtained from each patient or a relative of the patient before enrolment in the study. The indications for LDLT were: Hepatitis C Virus (HCV)related cirrhosis in 6 patients, including 2 patients with concomitant hepatocellular carcinoma (HCC) and 1 with concomitant intrahepatic cholangiocarcinoma; Hepatitis B Virus (HBV)-related cirrhosis in 3 patients, including 2 with concomitant HCC; cryptogenic cirrhosis in 5 patients; HBV-related fulminant hepatitis in 2 patients; alcohol-induced fulminant hepatic failure in 1 patient; and late-onset hepatic failure in 1 patient. There were 14 right lobe grafts and 4 left lobe grafts, and the graft type was selected based on a preoperative three-dimensional dynamic enhanced Computed Tomography (3D-CT) examination of the donor's liver in order to obtain a Graft-To-Recipient Body Weight Ratio (GRWR) above $0.8 \%$. Graft Volume $(\mathrm{GV})\left(\mathrm{cm}^{3}\right)$ was calculated from 3D-CT images of the donor's liver with High Speed Advantage QX-I volumetric software (GE Medical Systems, Tokyo, Japan). The GRWR (\%) was estimated preoperatively on the basis of the GV value, instead of graft weight, divided by the recipient's preoperative body weight $(\mathrm{g})$. The ABO blood types were compatible in every case. The preoperative mean Child-Pugh (CP) score [9] and mean Model for End-stage Liver Disease (MELD) score [10] were 11 (range: 7 to 15) and 19 (range: 6 to 37), respectively.

\section{Operation and portal venous pressure (PVP) monitoring}

Immediately after harvesting the liver grafts they were perfused via the portal vein with cold $\left(4^{\circ} \mathrm{C}\right)$ heparinized University of Wisconsin (UW) solution, weighed, and preserved in cold UW solution. GRWR was calculated postoperatively based on the actual weight of the graft. Before removing the recipient's liver, a 16-gauge antithrombotic catheter (Medicut UK-LCV kit; Nippon Sherwood Medical Industries, Tokyo, Japan) was inserted via the inferior mesenteric vein, and the tip of the catheter was advanced to the recipient's PV and fixed in place by ligation and with 2 rubber bands. The other end of the catheter was drawn outside the body through the wound, and connected to a transducer to continuously monitor PVP ( $\mathrm{mmHg}$ ). As a rule, the right Hepatic Vein (HV) was anastomosed to the Inferior Vena Cava (IVC) in an end-to-side fashion for right lobe grafts, and the common trunk of the left and middle HV was anastomosed to the IVC in an end-toside fashion for left lobe grafts. The PV was reconstructed by end-toend anastomosis, the hepatic artery (HA) by end-to-end anastomosis, and the bile duct by duct-to-duct anastomosis. Bile was drained outside the body via a 4 - or 5 -Fr silastic tube inserted throughout the anterior wall of the recipient's common bile duct. Since modulation of PVP is considered the key to success after LDLT, splenectomy was routinely performed in patients whose PVP was persistently elevated over 25 $\mathrm{mmHg}$ after the reconstructions, and 4 LDLT patients in this study underwent splenectomy. Bile was drained outside the body via a 4- or 5-Fr silastic tube through the cystic duct or the rubber T-tube after choledochotomy in the CDT control group.

\section{Postoperative care}

The immunosuppressive therapy protocol basically consisted of tacrolimus hydrate and a low-dose steroid. A peripheral venous blood examination was performed daily until POD 14. Bile was cultured for bacteria on POD 7. PVP was continuously monitored until POD 3 , and then 2 or 3 times a day from POD 4 to POD 7 with a Bed Side Monitor device (NIHON KOHDEN Co., Japan). The PV catheter was removed on POD 7 after collecting blood samples. In this study postoperative complications were defined as complications that occurred by POD 28 , and hospital death was defined as death during the hospital stay after LDLT. A non-contrast CT examination was performed on all patients on POD 28. GV was calculated from CT images by the same method as in the preoperative assessment. Standard liver volume (SLV) was calculated according to the formula proposed by Urata et al. [11]: SLV $\left(\mathrm{cm}^{3}\right)=$ body surface area $\left(\mathrm{m}^{2}\right)$ [height $(\mathrm{cm}) 0.725 \mathrm{x}$ body weight $(\mathrm{kg})$ $0.425 \times 0.007184] \times 706.2+2.4$. The ratio of GV to preoperative SLV (RGVSLV) on POD 28 was also calculated.

\section{Measurement of biliary sIg-A and portal venous IL-6}

On the morning of POD 7 a $3 \mathrm{ml}$ bile sample was collected into a sterile tube from the biliary drainage tube in the LDLT group and control group. The bile samples were centrifuged for 10 minutes at 3000 $\mathrm{rpm}$, and the supernatant was removed and stored at $-20^{\circ} \mathrm{C}$. The biliary sIg-A level of the stored supernatants was measured by the EnzymeLinked Immunosorbent Assay (ELISA) with the E.I.A. sIg-A Test (MBL Co., Ltd., Nagoya, Japan). On the morning of POD 7 a $1.5 \mathrm{ml}$ blood sample was collected from the PV catheter in the LDLT group into a sterile serum separator tube, to assay IL-6. The blood samples were immediately cooled to $0^{\circ} \mathrm{C}$ and then rapidly centrifuged for 5 minutes at $3000 \mathrm{rpm}$. The serum was separated and stored at $-70^{\circ} \mathrm{C}$. The serum IL-6 level was measured by a Chemiluminescent Enzyme Immunoassay (CLEIA) with a Human IL-6 CLEIA Kit (Fujirebio, Tokyo, Japan). The sIg-A and IL-6 assays were carried out at the Special Reference Laboratories Co (Hachioji, Tokyo, Japan).

\section{Statistical Analysis}

Values are expressed as means \pm standard deviation. Differences in biliary sIg-A values between the LDLT group and control group, and between subgroups according to the results of bacterial cultures of bile and postoperative complications were analyzed by Student's $t$-test. Correlations between the bile sIg-A levels and the various clinical data were assessed by Pearson correlation coefficients. Significance was considered to exist at $p$ values $<0.05$. The statistical analysis was performed with STATISTICA software for Macintosh (StatSoft Japan Inc., Tokyo, Japan). 
Citation: Yamagiwa K, lizawa Y, Kobayashi M, Shinkai T, Hamada T, et al. (2012) Evaluation of Biliary Secretory Immunoglobulin-A in Recipients of Living-Donor Liver Transplantation. J Liver 1:106. doi:10.4172/2167-0889.1000106

Page 3 of 4

\section{Results}

\section{Outcome of LDLT}

All specimens obtained from the liver grafts in this study were histologically confirmed to consist of normal liver tissue. Postoperative complications developed in 6 patients (33\%): abdominal abscess in 3 patients including 2 hospital deaths; thoracic abscess in 1 patient; Methiciln-resistant Staaphylococcus aureus bacteremia in 1 patient; acute rejection in 1 patient. In one of the two hospital deaths patients the HA was reconstructed intraoperatively three times because the HA intima had been injured. An abdominal abscess developed postoperatively after intra-abdominal bleeding, and the patient died at POD 30. In the other case the patient developed Pneumocystis carini pneumonia after POD 137, and died on POD 153. No postoperative complications developed in the control group.

\section{Biliary sIg-A values in the LDLT group and control group}

The biliary sIg-A levels $(\mathrm{mg} / \mathrm{ml})$ in the LDLT group $(102.8 \pm 74.8)$ were significantly higher $(\mathrm{p}=0.014)$ than in the CDT control group $(11.7$ \pm 5.6 ) (Figure 1). There were no significant differences between the biliary sIg-A levels of patients in the LDLT group according to whether the bile culture was positive or negative or whether the patients had developed postoperative complications (Table 1).

\section{Correlations between the biliary sIg-A levels and the clinical data (Table 2)}

Eleven variables, i.e., portal venous IL-6, PVP, CP score, MELD score, cold ischemic time, warm ischemic time, intraoperative blood loss, actual GRWR, serum Total Bilirubin (T-Bil) level, serum Alanine Aminotransferase (ALT) value, and RGVSLV, were investigated as clinical data. There were significant positive correlations between the biliary sIg-A levels and the IL-6 $(\mathrm{R}=0.6193, \mathrm{p}<0.006)$ (Figure 2$)$, PVP $(\mathrm{R}=0.5637, \mathrm{p}<0.015)$, and serum $\mathrm{T}-\mathrm{Bil}(\mathrm{R}=0.5326, \mathrm{p}<0.023)$ values. No other correlations were significant.

\section{Discussion}

The predominant immunoglobulin in bile is sIg-A [1]. The pathways

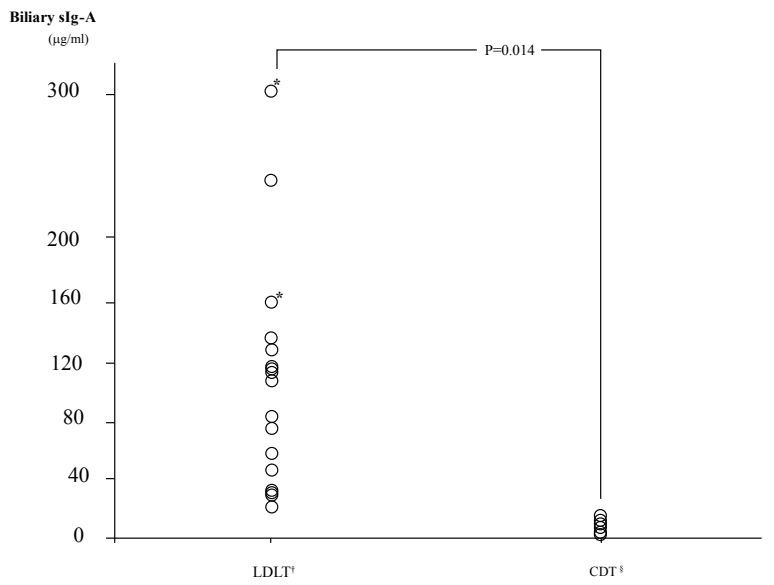

Figure 1: Distribution of the biliary secretory immunoglobulin (slg)-A values of patients in the $\mathrm{LDLT}^{\dagger}$ group and $\mathrm{CDT}^{\S}$ group on postoperative day 7 The biliary slg-A levels $(\mu \mathrm{g} / \mathrm{ml})$ in the LDLT group $(102.8 \pm 74.8 ; p=0.014)$ were significantly higher than in the CDT control group (11.7 5.6).

"Value of a hospital-death patient, LDLT': living-donor liver transplantation, CDTs: open choledochotomy and cholecystectomy, slg§: secretory immunoglobulin.

\begin{tabular}{|l|c|c|c|}
\hline Bile culture & Positive $(n=4)$ & Negative $(n=14)$ & $p$ value \\
\hline & $157.5 \pm 103.9$ & $87.4 \pm 60.2$ & 0.0987 \\
\hline Postoperative complication & yes $(n=6)$ & no $(n=12)$ & $p$ value \\
\hline & $129.2 \pm 98.8$ & $89.9 \pm 60.2$ & 0.3073 \\
\hline
\end{tabular}

*: Living Donor Liver Transplantation, †: Postoperative Day.

Table 1: Secretory immunoglobulin $A(\mu \mathrm{g} / \mathrm{ml})$ in the bile of the $\mathrm{LDLT}^{*}$ group on $\mathrm{POD}^{+} 7$.

\begin{tabular}{|c|c|c|c|}
\hline Variables & Value & Coefficient & $p$ value \\
\hline Portal venous $\mathrm{IL}^{\dagger}-6(\mathrm{pg} / \mathrm{ml})$ & $102 \pm 140$ & 0.6193 & $<0.006$ \\
\hline $\mathrm{PVP}^{\ddagger}(\mathrm{mmHg})$ & $18 \pm 6$ & 0.5637 & $<0.015$ \\
\hline $\mathrm{CP}^{\S}$ score & $11 \pm 2$ & 0.0648 & $<0.798$ \\
\hline MELD'score & $19 \pm 8$ & -0.2121 & $<0.398$ \\
\hline $\mathrm{CIT}^{\#}$ (min) & $152 \pm 110$ & 0.0002 & $<0.999$ \\
\hline WIT! (min) & $54 \pm 18$ & -0.2799 & $<0.261$ \\
\hline Intraoperative blood loss (ml) & $20098 \pm 18940$ & -0.0079 & $<0.975$ \\
\hline $\operatorname{GRWR}^{* *}(\%)$ & $1.02 \pm 0.23$ & -0.2538 & $<0.309$ \\
\hline Serum T-Bil ${ }^{\dagger \dagger l e v e l ~(m g / d l) ~}$ & $6.3 \pm 4.1$ & 0.5326 & $<0.023$ \\
\hline 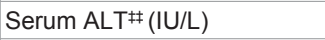 & $171 \pm 146$ & 0.1321 & $<0.601$ \\
\hline RGVSLV\$§ & $1.12 \pm 0.23$ & -0.2404 & $<0.337$ \\
\hline
\end{tabular}

": living-donor liver transplantation, †: interleukin, $\ddagger$ : portal venous pressure, §: Child-Pugh, ๆ: mathematical end-stage liver disease, \#: cold ischemic time, !: warm ischemic time, "*: actual graft-to-recipient body weight ratio, ††: total bilirubin, $\ddagger \ddagger$ alanine aminotransferase, $\S \S$ : ratio of graft volume to preoperative standard liver volume on postoperative day 28.

Table 2: Coefficients for the correlations between the bile secretory immunoglobulin A levels after LDLT* and clinical data.

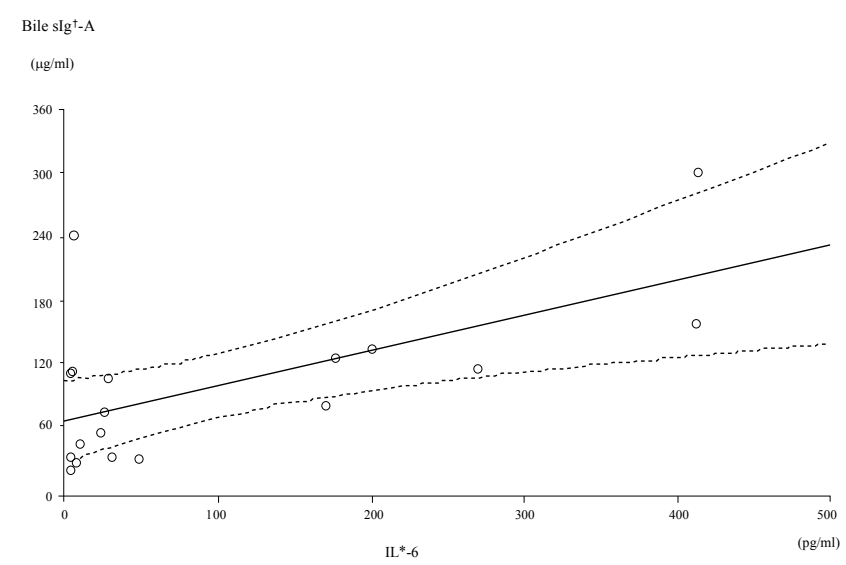

Figure 2: Correlation between portal venous $\mathrm{IL}^{*}-6$ levels and biliary slg'-A levels on day 7 after living-donor liver transplantation

There was a significant positive correlation $(p<0.006)$, and the correlation coefficient was 0.6193. The area between the dotted lines is the $95 \%$ confidence interval obtained by the Pearson correlation coefficient analysis.

IL*: interleukin, slg': secretory immunoglobulin.

by which Ig-A is transported into bile differ from species to species. In rats and mice the Ig-A produced by lymphoid tissue in the gut is cleared from the blood and transported into bile by pIgR located on the sinusoidal surface of hepatocytes [2]. In dogs, guinea pigs, and humans, on the other hand, sIg-A is synthesized locally by plasma cells along the biliary tree, binds to PIgR on the basolateral membrane of BECs, and is transported and secreted into the bile by the BECs, and there is much less hepatic transport of circulating Ig-A [2,3]. One important function of sIg-A in the intestine is to enhance the relative impermeability of the epithelium by binding to bacterial and enteric viral antigens in the gastrointestinal lumen [2]. The importance of biliary sIg-A in humans is largely unknown, but the following 3 functions of bile sIg-A have 
been proposed a) binding to extracellular pathogens and preventing their attachment to BECs, b) binding to free antigens to form immune complexes that facilitate their excretion, and c) binding to intracellular pathogens during their transcytosis [1].

In this study significantly higher biliary sIg-A levels at POD 7 were found in the LDLT group than in the CDT group, and the same finding as ours was reported by Perez et al. in OLT patients [5]. Secretion of Ig-A into bile is impaired in patients with cholestatic liver disease due to biliary obstruction and their serum sIg-A level is elevated [3]. Sung et al. found that biliary obstruction secondary to a calculus or hepato-biliary malignancy caused suppression of biliary Ig-A secretion and an elevated serum level of sIg-A, and that biliary sIg-A secretion had recovered by 1 week after relief of the obstruction by endoscopic drainage [12]. Based on their findings, the biliary sIg-A levels in the CDT group at POD 7 were thought to have recovered to normal levels in this study. Bresson-Handi et al. reported finding no significant differences between the biliary sIg-A levels of groups with rejection, infection, ischemia, or primary graft non-function, and no complications after OLT [6].

The present study revealed significant positive correlations between the biliary sIg-A levels and portal venous IL-6 levels in the LDLT group. Fujita et al. showed a positive correlation between peripheral venous sIg-A levels and portal venous IL-6 levels of 20 patients during major abdominal surgery (colorectal resection in 10 patients, gastrectomy in 8 patients, and pancreatoduodenectomy in 2 patients) [8]. Although they did not determine biliary sIg-A levels, they suggested that portal venous IL-6 stimulates the synthesis of sIg-A and/or return of sIg-A from bile into the systemic circulation in association with postoperative cholestatic liver damage [8]. The terminal differentiation of Ig- $\mathrm{A}^{+}$ plasma cells is driven by cytokines, especially IL- 5 and IL- 6 in the lamina propria [2]. Portal venous IL- 6 appeared to be produced by the endothelial cells lining intestinal veins when portal venous congestion was induced during the anhepatic phase of OLT [13]. Kawai et al. showed significantly higher IL-6 concentrations in the supernatant of cultured human liver Sinusoidal Endothelial Cells (SECs) and human umbilical vein endothelial cells that were exposed to stretch stress to mimic conditions after Portal Vein Embolization (PVE) than in the non-stretched control cells, and they suggested that the rapid elevation of PVP after PVE acted as a trigger for IL- 6 release by endothelial cells [14]. IL-6 has an effect on lymphocytes in the vicinity of the portal tract, and they are thought to promote terminal differentiation of Ig$\mathrm{A}^{+}$plasma cells and stimulate secretion of Ig-A into bile. Significant positive correlations between the biliary sIg-A levels and the PVP values, and serum T-Bil levels were also observed in the present study. High PVP of $20 \mathrm{mmHg}$ or more during the first 7 days after LDLT was demonstrated to be associated with rapid poor recipient outcome and graft dysfunction associated with hyperbilirubinemia [15]. High PVP after LDLT is considered the primary cause of increased secretion of portal venous IL-6 that leads to elevated biliary sIg-A levels and hyperbilirubinemia.

In conclusion, the results of this study showed significantly higher biliary sIg-A levels on POD 7 after LDLT than after open choledochotomy as the control group which is considering as normal biliary sIg-A levels. Significant positive correlations between the biliary sIg-A levels of LDLT patients and their portal venous IL-6 levels, the PVP values, and serum T-Bil levels were found on POD 7. The measurement of biliary sIg-A after LDLT is thought to be useful for analyzing postoperative complications with high PVP and hyperbilirubinemia.

\section{Acknowledgments}

This study was supported by grants from the Charitable Trust Surgical Research Foundation in 2002, Eisai Co., Ltd., Tokyo, Japan in 2003, and the Ajinomoto Pharma Co., Inc., Tokyo, Japan in 2003.

\section{References}

1. Wu CT, Davis PA, Luketic VA, Gershwin ME (2004)A review of the physiological and immunological function of biliary epithelial cells: targets for primary biliary cirrhosis, primary sclerosing cholangitis and drug-induced ductopenias. Clin Dev Immunol 11: 205-213.

2. Snoeck V, Peters IR, Cox E (2006) The IgA system: a comparison of structure and function in different species. Vet Res 37: 455-467.

3. Sung JY, Costerton JW, Shaffer EA (1992) Defense system in the biliary tract against bacterial infection. Dig Dis Sci 37: 689-696.

4. Chuang YH, Lan RY, Gershwin ME (2009) The immunopathology of human biliary cell epithelium. Semin Immunopathol 31: 323-331.

5. Perez JH, Schaik MV, Mullock BM, Bailyes EM, Price CP, et al. (1991) The presence and measurement of secretory component in human bile and blood. Clin Chim Acta 197: 171-187.

6. Bresson-Hadni S, Rossel M, Seilles E, Vuitton DA, Guennoune K et al (1991) Serum and bile secretory immunoglobulins and secretory component during the early postoperative course after liver transplantation. Hepatology 14: 10461053

7. Wu ZW, Ling ZX, Lu HF, Zuo J, Sheng JF, et al.(2012) Changes of gut bacteria and immune parameters in liver transplant recipients. Hepatobiliary Pancreat Dis Int 11: 40-50.

8. Fujita T, Kobayashi S, Saeki T, Itsubo K (1997) Relationship between circulating secretory immunoglobulin A levels and portal blood cytokine levels during major abdominal surgery. Arch Surg 132: 124-127.

9. Pugh RN, Murray-Lyon IM, Dawson JL, Pietroni MC, Williams R (1973) Transection of the oesophagus for bleeding oesophageal varices. $\mathrm{Br} \mathrm{J}$ Surg 60: 646-649.

10. Freeman RB Jr, Wiesner RH, Harper A, McDiarmid SV, Lake J, et al. (2002 The new liver allocation system: moving toward evidence-based transplantation policy. Liver Transpl 8: 851-858

11. Urata K, Kawasaki S, Matsunami H, Hashikura Y, Ikegami T, et al. (1995) Calculation of child and standard liver volume for liver transplantation. Hepatology 21: 1317-1321.

12. Sung JJ, Leung JC, Tsui CP, Chung SS, Lai KN (1995) Biliary IgA secretion in obstructive jaundice: the effects of endoscopic drainage. Gastrointest Endosc 42: $439-444$

13. Steininger R, Roth E, Függer R, Winkler S, Längle F, et al. (1994) Transhepatic metabolism of TNF- $\alpha$, IL-6, and endotoxin in the early hepatic reperfusion period after human liver transplantation. Transplantation 58: 179-183.

14. Kawai M, Naruse K, Komatsu S, Kobayashi S, Nagino M, et al. (2002) Mechanical stress-dependent secretion of interleukin 6 by endothelial cells after portal vein embolization: clinical and experimental studies. J Hepatol 37 240-246.

15. Yagi S, lida T, Taniguchi K, Hori T, Hamada T, et al. (2005) Impact of porta venous pressure on regeneration and graft damage after living-donor liver transplantation. Liver Transpl 11: 68-75 